\title{
Entre a Filosofia e a Ciência: Merleau-Ponty e a Psicologia
}

\author{
Danilo Saretta Verissimo \\ Reinaldo Furlan \\ Universidade de São Paulo, Ribeirão Preto-SP, Brasil
}

\begin{abstract}
Resumo: Merleau-Ponty abordou um problema da tradição filosófica que se agudizou após o desenvolvimento das ciências humanas: a discordância entre a visão que o homem pode ter de si mesmo pela reflexão ou consciência e aquela que se obtém relacionando suas condutas às condições externas das quais elas dependem. Merleau-Ponty procurou resolver essa discordância à luz das próprias experiências das ciências, particularmente, da psicologia. Segundo ele, essas experiências demandam uma revisão da ontologia moderna. Neste contexto, no presente artigo, abordamos algumas facetas do diálogo estabelecido por Merleau-Ponty com a psicologia. Apresentamos uma leitura de questões tratadas, sobretudo em seus trabalhos iniciais.
\end{abstract}

Palavras-chave: Fenomenologia e psicologia. Epistemologia da psicologia. Merleau-Ponty.

\section{Between Philosophy and Science: Merleau-Ponty and Psychology}

\begin{abstract}
Merleau-Ponty approached a philosophical tradition problem that has become critical after the development of human sciences, that is, the discordance between the view man can have of himself through reflection or conscience and the view obtained by relating behavior to the external conditions it depends on. Merleau-Ponty tried to solve this discordance in the light of scientific experimentation, mainly that of psychology. According to him, scientific experimentation demands a review of modern ontology. In this frame, the present paper addresses some of the facets of the dialogue established by Merleau-Ponty with psychology by presenting an interpretation of the subjects treated by the author, especially in his initial writings.
\end{abstract}

Keywords: Phenomenology and psychology. Epistemology of psychology. Merleau-Ponty.

\section{Entre la Filosofía y la Ciencia: Merleau-Ponty y la Psicología}

Resumen: Merleau-Ponty abordó un problema de la tradición filosófica que agudizo después del desarrollo de las ciencias humanas: la discordancia entre la visión que el hombre pode tener de si mismo pela reflexión o conciencia, y aquella que se obtiene relacionando sus conductas a las condiciones externas de las cuales ellas dependen. Merleau-Ponty intentó resolver ese desacuerdo a la luz das propias experiencias de las ciencias, particularmente, con la psicología. Según él, esas experiencias exigen una revisión de la moderna ontología. En este contexto, en el presente artículo, abordamos algunas facetas del diálogo establecido por Merleau-Ponty con la psicología. Presentamos una lectura de las cuestiones por él tratadas, sobretodo en sus trabajos iniciales.

Palabras clave: Fenomenología y psicología. Epistemología de la psicología. Merleau-Ponty. 


\section{Introdução}

Neste artigo, abordamos algumas facetas do diálogo estabelecido pelo filósofo francês Maurice Merleau-Ponty (1908-1961) com a psicologia, dado que, ao longo da sua obra, interrogou-a maciçamente, discutindo seus métodos, os seus alcances e a noção de ser que dela emerge. Apresentamos uma leitura de questões tratadas, sobretudo, em seus dois primeiros trabalhos, A Estrutura do Comportamento (Merleau-Ponty, 1942/1975) e Fenomenologia da Percepção (Merleau-Ponty, 1945/1999).

\section{Entre a Filosofia e a Ciência}

Em seus escritos, Merleau-Ponty privilegiou, sempre, o debate com o legado cartesiano na filosofia e nas ciências. Abordou, fundamentalmente, um problema constante na tradição filosófica e que se agudizou após o desenvolvimento das ciências do homem, levando a uma crise do nosso saber e, ao mesmo tempo, da filosofia. Trata-se da discordância entre a visão que o homem pode ter de si mesmo pela reflexão ou pela consciência e aquela que se obtém ligando suas condutas às condições externas das quais elas, manifestamente, dependem. Em última instância, para Merleau-Ponty, tratava-se de compreender como o homem pode ser simultaneamente "sujeito" e "objeto" (Bimbenet, 2004).

Este problema é uma herança cartesiana, desde que o homem foi definido pelo mistério da união entre a alma e o corpo. Tal mistério foi radicalizado, elevado à altura de um mistério especulativo, uma verdadeira antinomia que deságua em dois pontos de vista irreconciliáveis sobre o ser: de um lado, o ponto de vista interior ou idealista da reflexão filosófica, de outro, o ponto de vista exterior ou realista da ciência. Dessa maneira, é possível afirmar que o legado de Descartes aos seus sucessores é um campo de conhecimento essencialmente problemático, pois uma ciência do homem teria que reunir um conjunto de ciências declaradamente irredutíveis: de um lado, aquelas da natureza física do homem, de outro, aquelas da substância pensante.

O divórcio radical, no século XIX, entre a filosofia e a ciência deve-se, justamente, ao fato destes dois protagonistas possuírem a mesma ambição. Tanto a filosofia espiritualista, quanto a ciência experimen- tal, buscavam, sozinhas, totalizar o fenômeno humano, a primeira a partir do poder de animação do espírito, a segunda a partir do enraizamento fisiológico da consciência (Bimbenet, 2004).

Dessa forma, o tema antropológico, o fenômeno humano, aparece sob a forma de uma antinomia. Ele é inaugurado em meio a uma crise que afeta o saber. Japiassu (1977), referindo-se a esta crise, comenta que a antropologia, em seu sentido geral, passou a oscilar "(...) entre um conhecimento organicista e materialista do ser corporal e biológico do homem, e um saber espiritualista da vida psíquica, intelectual e moral da 'alma' humana, ligando os dois de modo mais ou menos bastardo no plano da objetividade" (p. 24).

Merleau-Ponty instalou-se nesta crise e buscou construir uma reflexão rigorosa que requeresse um saber crítico sobre a problemática apresentada. Para tanto, recusou-se a tomar parte em um ou em outro ponto de vista. Mergulhou em ambos com o intuito de denunciar estes dois mitos antagonistas e cúmplices: o mito da filosofia e o mito do saber científico (Bimbenet, 2004).

Ao final da sua vida, Merleau-Ponty dedicava-se a uma obra (Merleau-Ponty, 2003) que, mesmo inacabada, nos esclarece acerca da intenção do autor de retomar suas antigas análises, frutos dos seus primeiros trabalhos, ligando-as em uma nova ontologia. Em suas páginas, levadas a público postumamente, ainda se entrevê o seu esforço para penetrar os domínios que o pensamento habitual não deixa imediatamente acessíveis. Nelas, Merleau-Ponty persiste na tese de que os conceitos fundamentais da filosofia moderna, tais como as distinções entre sujeito e objeto, fato e essência, e as noções de consciência e de coisa, implicam em uma interpretação do mundo impotente diante do propósito de colocar-nos face à experiência vivida (Lefort, 2003). Numa passagem que revela uma das intenções centrais que anima toda a sua obra, diz:

Nosso objetivo não é opor aos fatos coordenados pela ciência objetiva outro grupo de fatos - sejam eles chamados 'psiquismo' ou 'fatos subjetivos', ou 'fatos interiores' - que 'lhe escapam', mas mostrar que o ser-objeto e também o sersujeito, este concebido em oposição àquele 
e relativamente a ele, não constituem uma alternativa, que o mundo percebido está aquém ou além da antinomia, que o fracasso da psicologia 'objetiva' deve ser compreendido juntamente com o fracasso da física 'objetivista' - não como uma vitória do 'interior' sobre o 'exterior', do 'mental' sobre o 'material', mas como apelo à revisão de nossa ontologia, ao reexame das noções de 'sujeito' e de 'objeto'. As mesmas razões que impedem de tratar a percepção como um objeto, também impedem de tratála como operação de um 'sujeito', seja qual for o sentido em que possa ser tomada (Merleau-Ponty, 2003, p. 32).

\section{A aproximação com a psicologia}

Com base em relatórios apresentados por Merleau-Ponty (1990) para a obtenção de uma subvenção para pesquisa e sua renovação, no ano seguinte, pela Caixa Nacional de Ciência, na França, notamos que, já entre 1933 e 1934, o então jovem filósofo dedicava-se aos estudos da "Gestaltpsychologie", que para ele representavam uma importante contribuição para a questão da percepção e, assim, para a renovação da concepção do espírito, dominada na época pelo criticismo (Kant) tanto na filosofia como na psicologia (intelectualismo). Registra-se, nesse período, o estudo da psicologia da percepção e da psicopatologia, com exemplos ${ }^{1}$ que veremos surgir, posteriormente, em suas duas primeiras obras, A Estrutura do Comportamento (MerleauPonty, 1942/1975) e Fenomenologia da Percepção (Merleau-Ponty, 1945/1999). A psicologia alemã, representada pela "Gestaltpsychologie", mostrava, nos trabalhos de Kofka, Köhler e Wertheimer, entre outros, que a percepção não é a sobreposição de uma forma (intelecção) sobre um material sensível (sensação), mas que a forma está na matéria da percepção e é anterior a qualquer ato de intelecção. "A Escola de que nos ocupamos explica (...) pelo fator psi-

\footnotetext{
1 "Dentre muitos outros problemas que a psicopatologia coloca, deveria ser retomado o problema da ilusão dos amputados" (Merleau-Ponty, 1990, p. 13). De fato, a questão do membro fantasma foi foco de profundas análises do autor na Fenomenologia da Percepção (Merleau-Ponty, 1945/1999).
}

cológico chamado Gestalt o que a antiga psicologia reputava à interpretação e ao julgamento" (MerleauPonty, 1990, p. 24). A partir dos trabalhos de Gelb e Goldstein, neurofisiólogos alemães, Merleau-Ponty adentrava, com o mesmo princípio, nos estudos da fisiologia nervosa e na patologia do comportamento.

Também data dessa época a leitura da fenomenologia de Husserl, que deveria contribuir para o esclarecimento do sentido das experiências psicológicas. Não se tratava de substituir a psicologia e o método indutivo, no sentido amplo do termo, mas de contribuir para o esclarecimento do campo de suas pesquisas, e daí, segundo Merleau-Ponty, a distinção de Husserl entre uma psicologia eidética e uma psicologia experimental, a primeira encarregada da obtenção da essência geral dos fenômenos, e a segunda encarregada dos seus sentidos particulares, o que, vale lembrar, reproduz a distinção kantiana entre o transcendental e o empírico. Mas o interesse de Merleau-Ponty pelas ciências, em particular por essas experiências da psicologia com que inicia suas investigações filosóficas, já mostrava a relação profícua que haveria entre a fenomenologia e a psicologia experimental em seu pensamento, prenúncio da diferença com a fenomenologia de Husserl que se confirmaria, depois, na recusa da possibilidade de distinção entre fato e essência, empírico e transcendental.

Enfim, assistimos Merleau-Ponty adentrar os meandros da neurologia e da psicologia experimental, particularmente da psicopatologia para "(...) retomar o problema da percepção e particularmente da percepção do corpo próprio (...)" (Merleau-Ponty, 1990, p. 11), com os quais esperava não apenas “(...) reformular certas noções psicológicas e filosóficas correntes (...)" (Merleau-Ponty, 1990, p. 13), mas também a própria concepção do conhecimento.

De fato, n'A Estrutura do Comportamento (1942/1975) e na Fenomenologia da Percepção (1945/ 1999), Merleau-Ponty pôs em marcha a sua tentativa de retomada do fenômeno humano em detrimento das antinomias da metafísica clássica, que opõem a consciência e a natureza, o pensamento e a extensão, e abrem espaço para toda sorte de dicotomias.

Se, na primeira obra, Merleau-Ponty propõese a compreender os laços entre a consciência e a natureza, na segunda, o ato perceptivo apresenta-se 
como um ato emblemático por reconciliar, silenciosa e peremptoriamente, as duas instâncias. $O$ fato é que, para denunciar as referidas dicotomias da metafísica clássica, Merleau-Ponty entra em contato, profundamente, com o ponto de vista da ciência positiva, cuja abordagem da consciência revela-a como uma região do ser e como um ente de parte a parte natural, e com o ponto de vista reflexivo da filosofia, que afirma a autonomia da consciência.

Deste modo, n'A Estrutura do Comportamento, em uma crítica trançada pacientemente e calcada na noção de estrutura, Merleau-Ponty ultrapassa o realismo em direção do ponto de vista da consciência. E, de maneira análoga, na Fenomenologia da Percepção, agora sob maior influência da fenomenologia de Husserl, ele parte da perspectiva da consciência para, progressivamente, esvaziá-la de suas prerrogativas e sujeitá-la aos poderes naturais do corpo próprio. Assim, estas duas obras partem das dicotomias para melhor desqualificá-las. Desta forma, elas alcançam, de modo convergente, o centro comum da consciência e da natureza. Nos dois casos, prevalece a exigência descritiva ${ }^{2}$ e, também, uma inclinação arqueológica (Bimbenet, 2004).

É importante sublinhar que, a partir d'A Estrutura do Comportamento, Merleau-Ponty inicia um debate rigoroso, crítico e sistemático com o realismo presente na psicologia científica. É assim que assistimos ao autor analisar, com grande perspicácia, as

\footnotetext{
${ }^{2} \mathrm{O}$ método descritivo, tal como apresentado por MerleauPonty (1945/1999), é uma herança direta da filosofia de Husserl e visa contrapor-se aos métodos de análise elementar da ciência clássica da percepção. Nesta, o real é concebido partes extra partes, e a percepção concebida como resultado da ação dos estímulos parciais sobre o aparelho perceptivo. Para a fenomenologia, ao contrário, é preciso descrever e não explicar o fenômeno perceptivo, uma vez que, despindo-se de qualquer pressuposto sobre a realidade, trata-se de apreender o seu sentido, a maneira como ele se mostra. A percepção não se realiza sem determinadas condições, mas não são estas que a explicam. Neste sentido, Merleau-Ponty fala em uma descrição direta do sentido da experiência, o que também não quer dizer imediata, uma vez que a sua apreensão geralmente requer muitas mediações de sentido. O que se quer evitar é o recurso a explicações causais ou psicológicas acerca de sua gênese. Esta exigência descritiva sustenta um discurso compreensivo, que tem por meta a retomada do modo único e estrutural de existência que transparece nas coisas.
}

psicologias da época: a psicofisiologia dos comportamentos elementares e superiores, a psicologia do comportamento animal, a psicologia da forma, a psicologia genética, a psicopatologia e a psicanálise (Bimbenet, 2004). Os textos de psicologia reaparecem na Fenomenologia da Percepção, trabalho em que se abre, ainda, uma nova perspectiva, na medida em que o filósofo reconhece uma psicologia e uma psiquiatria fenomenológicas, com a citação freqüente de Minkowski e Binswanger, entre outros. Nela, também a psicanálise surge como uma teoria que, em alguns aspectos, aproxima-se de uma filosofia fenomenológica.

Portanto, as duas primeiras obras de MerleauPonty revestem-se de especial interesse para nós. Coelho Júnior e Carmo (1991) tecem a seguinte referência a elas: “(...) devemos nos deter em suas duas e fundamentais obras onde a psicologia, mais do que um reconhecimento, recebe uma contribuição crítica filosófica que mereceria ser melhor estudada pelos psicólogos" (p. 39). Merleau-Ponty considerava indispensável a mediação e o desvio de sentido oferecido pelas diversas ciências para o desvelamento do sentido do mundo e de nós mesmos e, conforme suas observações (Merleau-Ponty, 1942/1975), pelas vias rápidas da reflexão do "cogito", não se chegaria ao saber da encarnação do espírito que as experiências da psicologia da percepção, da psicologia da criança e da psicopatologia lhe permitiam descobrir.

\section{O comportamento em foco}

A ciência é construída em meio a uma metafísica que o cientista, normalmente, assume como dada. Contudo, o seu desenvolvimento pode sinalizar outras formas de compreensão do fenômeno, formas não estabelecidas nos quadros da metafísica da qual o cientista é herdeiro. Assim, o desenvolvimento da ciência pode apontar a necessidade de uma revisão ontológica, e, em certa perspectiva, é isso que Merleau-Ponty procura mostrar por meio da análise fenomenológica das experiências realizadas pelas ciências do comportamento. Num primeiro passo da sua trajetória filosófica, o autor francês procurou realizar uma leitura do sentido do comportamento fora do quadro da metafísica clássica.

Para Merleau-Ponty (1942/1975), a noção de comportamento é neutra face às distinções clássicas 
do "psíquico" e do "fisiológico", o que levanta a oportunidade de redefini-las. Tal ponto de vista é profícuo desde que se trate de elucidar diretamente a noção de comportamento, sem traçar os mesmos rumos da psicologia norte-americana. Aliás, é importante segui-los, diz o autor, mas com o intuito de conhecer por qual desordem ideológica esta noção foi desenvolvida em seu país de origem.

Inicialmente, ainda com Watson, havia algo de sadio e de profundo na intuição do comportamento. Dizia-se que este não está localizado no sistema nervoso central, mas entre o indivíduo e o meio ambiente, o que tornava possível o estudo do comportamento sem menções à fisiologia. Dizia-se, ainda, que ele versa sobre um fluxo de ação, projetado pelo vivente à sua volta, que afeta os estímulos com um sentido particular e os incorpora à resposta. Mas, esta visão do homem como debate perpétuo com um mundo físico e social não resistiu muito.

Em reação contra as trevas da intimidade psicológica, o behaviorismo não procura recursos, a maior parte do tempo, senão em uma explicação fisiológica ou mesmo física, sem ver que ela está em contradição com as definições iniciais - ele se declara materialista, sem ver que isto consiste em recolocar o comportamento no sistema nervoso. Em nossa opinião (...), Watson tinha em vista, quando falava de comportamento, o que os outros chamaram de existência, e a nova noção não podia receber seu estatuto filosófico senão se abandonasse o pensamento causal ou mecânico pelo pensamento dialético (Merleau-Ponty, 1942/ 1975, p. 31, grifo do autor).

A psicologia quis ser uma ciência natural e, assim, permaneceu fiel ao realismo e ao pensamento causal.

A análise científica do comportamento se estabeleceu por oposição aos dados da consciência ingênua. O comportamento, assimilado a partir do interior, parece orientado por uma intenção, por um sentido. Pensemos numa mancha luminosa em uma sala escura, conforme o exemplo dado por Merleau-Ponty (1942/1975). Diremos que ela "atrai" minha atenção, que volto meus olhos "na sua direção", que os seus movimentos "arrastam" o meu olhar. Contudo, estes caracteres são repelidos pela ciência como aparências sob as quais se oculta uma realidade de um gênero diferente. Dir-se-á que a luz encobre um movimento vibratório que não é jamais dado à consciência. À aparência qualitativa convencionou-se denominar luz fenomenal, enquanto o movimento vibratório recebe o nome de luz real. Como a luz real não é percebida, ela não pode se apresentar como um fim ao qual o meu comportamento se orienta. "Ela não pode ser pensada senão como uma causa que age sobre o meu organismo" (Merleau-Ponty, 1942/1975, p. 33).

A análise científica decompõe o estímulo, no caso, a mancha luminosa, em diversos processos parciais compatíveis com os vários elementos anatômicos que se encontram sob a retina. Entende-se, então, que a luz, tocando minha retina, desencadeia um mecanismo pronto a funcionar. Dessa forma, se, com o deslocamento da mancha, meus olhos se deslocam, devemos compreender o fenômeno sem introduzir nele nada que se assemelhe a uma intenção.

Esta representação científica do organismo conduziu-nos à teoria clássica do reflexo. Nela, temse a decomposição da excitação e da reação em uma infinidade de processos parciais, exteriores uns aos outros. O reflexo surge, assim, como a operação de um agente físico ou químico definido sobre um receptor definido, que provoca, por um trajeto bem demarcado, uma resposta também definida.

Para compreendermos melhor estes primórdios da psicologia, lembremos, com Japiassu (1977), que, inicialmente, ela estava ligada à filosofia, constituindo uma espécie de antropologia filosófica. Ocupava-se em descrever os comportamentos em termos de faculdades inatas transcendentes, como a vontade, o conhecimento, o instinto, e a percepção. Com o intuito de libertar-se da filosofia, a psicologia, no século XIX, aliou-se a uma perspectiva dita científica cujo campo epistemológico era fornecido pelas ciências experimentais de ordem psicofísica ou psicofisiológica, estas já possuidoras de um estatuto científico reconhecido. Desde a época moderna clássica, a matemática e a física forneciam à inteligência os modelos de cientificidade, eram elas que proporcionavam o solo epistemológico sobre o qual se julgava o caráter mais ou menos científico das diversas práticas do conhecimento. 
Para Politzer (1929/1975), autor muito citado por Merleau-Ponty, a psicologia clássica é marcada pela abstração e pelo formalismo. Diz ele que o emprego da matemática pela psicologia configura um uso de "terceira mão", já que ela o herdara dos físicos e dos fisiólogos. O mesmo é válido em relação ao método experimental. Segundo o autor, o conjunto das operações explicativas no seio desta nova ciência configura uma abstração, um método da terceira pessoa, pois elimina o sujeito na medida em que considera seus fenômenos como sendo produzidos por causas impessoais, atitude essa adotada para explicar os fatos objetivos em geral. Politzer (1929/1975) comenta, ainda, que a análise formal do comportamento não dá atenção à sua individualidade, fornecida pelo seu sentido.

Merleau-Ponty (1942/1975) destacou, então, a noção de forma por permitir novas soluções nas investigações sobre o comportamento. Com base nas formulações da "Gestaltpsychologie", ou psicologia da forma, e nas acepções estruturais da biologia organicista de autores como Goldstein, Merleau-Ponty apresentou-nos um pensamento estrutural calcado na relação ativa do comportamento com o seu entorno. Segundo o autor, entre a situação e a resposta vemos se estabelecer uma ligação dialética de sentido entre o organismo e o meio, relação de reciprocidade e interatividade. Assim, o que Merleau-Ponty nos faz ver é que todo comportamento deixa reconhecer uma forma, ou uma ligação interior e significante entre a situação e a reação. Nesta perspectiva, o filósofo pôde abordá-lo estruturado na ordem vital, que se refere aos organismos de modo geral, e na ordem humana, que diz respeito ao comportamento do homem, e não a partir de noções que somente encontram sentido no campo físico, a primeira forma na hierarquia das ordens. Já na análise do comportamento animal, percebe-se que “(...) as reações de um organismo não são conjuntos de movimentos elementares, mas gestos dotados de uma unidade interior" (Merleau-Ponty, 1942/1975, p. 166). A experiência de um organismo não comporta a fixação de movimentos realizados e, sim, a elaboração de aptidões, ou seja, o poder geral de responder a situações por reações diversas, que têm em comum o seu sentido. A situação e a reação não admitem a análise em termos de causa e efeito. "Não se pode mesmo, se o comportamento é uma 'forma', assinalar nele aquilo que depende de cada uma das condições internas ou externas tomadas à parte, pois suas variações aí se traduzem por um efeito global e indivisível", diz Merleau-Ponty (1942/1975, p. 167).

Mas, a psicologia da forma também recebeu análises críticas por parte de Merleau-Ponty. Segundo o autor, ela não teria levado longe um trabalho de análise filosófica, empresa que demandava liberdade em relação aos postulados realistas da psicologia.

A "Gestalt" teve início na Alemanha, concomitantemente ao comportamentalismo de Watson nos Estados Unidos. Nasceu da contraposição ao atomismo da psicologia clássica wundtiana. A "Gestalt" também sofreu uma significativa influência da física, mas da física que, a partir das últimas décadas do século XIX, passou a reconsiderar a noção de atomismo, ou elementarismo, e que começava a pensar em termos de campos. Buscando a superação do método de análise elementar, a Gestalt, como o próprio nome sugere, considerou a forma ou estrutura como expressão originária da realidade. Na sua concepção, os dados perceptivos e mesmo os fatos psíquicos compõem uma unidade com articulação interna que depende tanto de condições objetivas quanto de condições subjetivas, sendo que alterações nessas condições repercutem na forma ou estrutura de que participam (Guillaume, 1937/1966). De qualquer maneira, novamente, os psicólogos esforçavam-se para acompanhar as ciências naturais. Köhler (conforme citado por Schultz e Schultz, 1995), um dos mais significativos representantes da "Gestalt", assim referiu-se a tal relação: "a psicologia da Gestalt se tornou uma espécie de aplicação da física dos campos a partes essenciais da psicologia" (p. 77).

Entrementes, a noção de forma, aplicada à percepção, levantou uma idéia importante e que foi desenvolvida por Merleau-Ponty. Trata-se de afirmar que a experiência perceptiva carrega consigo uma integralidade e uma completude que não pode ser encontrada em nenhuma das suas partes, e que cada um dos seus termos é determinado pelas leis totais da experiência (Schultz \& Schultz, 1995).

Mas, retornemos às críticas de Merleau-Ponty à psicologia da forma. Conforme as suas análises, esta psicologia permaneceu exigindo modelos físicos para suportar no ser as formas fisiológicas ou psíquicas. Nela, o comportamento permanece como uma província do universo físico. 
A teoria da forma pensa ter resolvido o problema das relações entre a alma e o corpo e o problema do conhecimento perceptivo, descobrindo processos nervosos estruturais que de um lado tenham a mesma forma que o psíquico e de outro sejam homogêneos às estruturas físicas. Nenhuma reforma da teoria do conhecimento seria então necessária e o realismo da psicologia como ciência natural seria conservado a título definitivo (MerleauPonty, 1942/1975, p. 170).

Nesta perspectiva, a tomada de consciência não representa um acréscimo em relação às estruturas físicas, mas tão somente o índice de estruturas físicas particularmente complexas. Por isso a afirmação de Merleau-Ponty de que a noção de "Gestalt" não foi seguida até suas mais importantes conseqüências.

Na visão de Merleau-Ponty (1942/1975), a noção de forma integra aqueles três campos, o físico, o vital e o humano, enquanto três tipos de estruturas, três diferentes dialéticas. Em relação aos sistemas físicos, falamos de um conjunto de forças em equilíbrio ou em mudança constante. Nenhuma lei é formulável para cada parte tomada isoladamente em um sistema. Cada vetor é determinado pelos outros. Assim, uma mudança local se traduz em uma nova forma pela redistribuição das forças que assegura a constância da sua relação.

Quanto às estruturas orgânicas, deparamo-nos com uma segunda dialética. $\mathrm{O}$ organismo deve ser considerado em relação à tarefa na qual se encontra engajado.

As relações entre o indivíduo orgânico e seu meio são pois verdadeiramente relações dialéticas e esta dialética faz aparecer relações novas, que não podem ser comparadas àquelas de um sistema físico e de seu entorno, nem mesmo compreendidas quando se reduz o organismo à imagem que a anatomia e as ciências físicas lhe dão. Suas reações, mesmo elementares, não podem ser classificadas, dissemos, segundo os aparelhos nos quais elas se realizam, mas segundo sua significação vital (Merleau-Ponty, 1942/1975, p. 185).
Em um outro trecho, o filósofo diz:

Queremos dizer apenas que as reações de um organismo não são compreensíveis e previsíveis a não ser se são pensadas, não como contrações musculares que se desenrolam em um corpo, mas como atos que se endereçam a um certo meio, presente ou virtual: $o$ ato de capturar uma presa, de andar em direção a um objeto, de fugir de um perigo (Merleau-Ponty, 1942/1975, p. 187).

Assim, a compreensão das entidades biológicas passa pela vinculação do conjunto de fatos conhecidos por sua significação. Os argumentos mecanicistas tomam o organismo como um produto real de uma natureza exterior, enquanto ele é uma unidade de significação.

$\mathrm{Na}$ ordem humana, encontramos uma terceira dialética. Neste campo, Merleau-Ponty (1942/1975) inicia uma discussão acerca da noção de consciência, buscando contrapor-se a noções dicotômicas como a de consciência enquanto posse de um objeto de pensamento ou ente transparente a si mesmo, e a noção de ação enquanto série de acontecimentos exteriores entre eles. Na intenção de conceber a estrutura da consciência, o filósofo passa a analisar os caracteres descritivos da percepção humana, concebida como um momento da dialética viva de um sujeito concreto. Nossa percepção, diz o autor, é guiada para a significação humana das coisas e dos sujeitos e não para sinais sensíveis. Dessa maneira, Merleau-Ponty deseja mostrar que o índice da existência humana encontra-se no aspecto fenomenal do percebido e em seu sentido intrínseco. Além disso, o autor mostra que a ação e a percepção humanas são irredutíveis à dialética do organismo e do seu meio físico.

A relação entre cada ordem e a ordem superior é a do parcial ao total. O homem normal não é um corpo portador de certos instintos autônomos, unido a uma 'vida psicológica' definida por certos processos característicos, - prazer e dor, emoção, associação de idéias, - e dominado por um espírito que desenvolveria seus atos próprios sobre esta infraestrutura. O advento das ordens superiores, na medida em que se 
realiza, suprime como autônomas as ordens inferiores e dá às demarches que as constituem uma significação nova. É por isso que falamos de uma ordem humana, antes que de uma ordem psíquica ou espiritual. (...) já a biologia, nós o vimos, refere-se ao corpo fenomenal, isto é, a um centro de ações vitais que se estendem sobre um segmento de tempo, respondem a certos conjuntos concretos de estímulos e fazem colaborar todo o organismo. Esses modos de comportamento não subsistem tais quais mesmo no homem. Reorganizados por sua vez em conjuntos novos, os comportamentos vitais desaparecem como tais. É o que significam por exemplo a periodicidade e a monotonia da vida sexual entre os animais, sua constância e suas variações no homem (Merleau-Ponty, 1942/ 1975, p. 214).

Merleau-Ponty, desenvolvendo as implicações da representação científica do comportamento humano, pretendeu denunciar a artificialidade das alternativas da psicologia, que, depois de estruturar-se como ciência dos fatos de consciência, tornou-se, com Watson, psicologia sem consciência. Quando o comportamento é tomado em sua unidade e em seu sentido humano, não se trata mais de uma realidade material, ou de uma realidade psíquica, mas de um conjunto significativo.

\section{Percepção, corpo próprio e ambigüidade}

Em A Estrutura do Comportamento, como dissemos, Merleau-Ponty (1942/1975) partiu do realismo da psicologia para alcançar a noção de consciência. Já na Fenomenologia da Percepção, tratou-se de compreender como a consciência se mostra inserida em uma natureza.

Nesta segunda obra, o foco inicial do filósofo foi o fenômeno da percepção, que, segundo ele, as análises clássicas deixaram escapar desde que admitiram uma série de noções confusas, como a de sensação. Na medida em que as reflexões de MerleauPonty avançam, ele nos convida a reportarmo-nos ao corpo do qual temos experiência e que não cessa de se dirigir ao mundo, corpo este que o filósofo denominou de "corpo próprio".
Segundo o filósofo, a consciência científica erige por objeto de análise o mundo objetivo e, dessa forma, mais mascara a subjetividade do que a revela. A ciência introduz, por exemplo, sensações, que são coisas, onde a experiência aponta a existência de conjuntos significativos, sujeitando o universo fenomenal a categorias que somente encontram nexo no universo científico. Não vê que a ambigüidade e a liberdade para se modelar segundo o seu contexto são fatores próprios do percebido. Por isso mesmo que há lacunas na percepção que somente são identificáveis para uma percepção analítica, que não é a natural. É assim que uma teoria da sensação, por exemplo, constrói objetos limpos de quaisquer equívocos, puros e absolutos, frutos antes de um ideal do conhecimento do que seus temas efetivos. Tanto é assim que algumas questões presentes nas pesquisas realizadas nos laboratórios de psicologia somente se impõem no mundo objetivo, em um mundo tomado em si em que tudo é determinado.

Com efeito, em seu esforço de objetivação, a ciência acaba por representar o organismo humano como um sistema físico face a estímulos definidos por suas propriedades físico-químicas. E é sobre esta base que pretende reconstruir a percepção efetiva. Seu objetivo último é fechar o ciclo de conhecimento científico, descobrindo as leis da produção do próprio conhecimento e, deste modo, fundar uma ciência objetiva da subjetividade. Mas, para Merleau-Ponty (1945/1999), é inevitável que essa tentativa fracasse, exigindo um outro tipo de inteligibilidade para dar conta do fenômeno perceptivo.

É ora a aderência do percebido a seu contexto e como que sua viscosidade, ora a presença nele de um indeterminado positivo, que impedem os conjuntos espaciais, temporais e numéricos de se articularem em termos manejáveis, distintos e identificáveis. E é este domínio préobjetivo que precisamos explorar em nós mesmos se queremos compreender o sentir (Merleau-Ponty, 1945/1999, p. 34).

As teses intelectualistas, que pressupõem uma consciência constituinte absoluta, também não lançam sobre a percepção um olhar direto. Nelas, a percepção aparece, sobretudo, como uma interpretação 
dos signos. Mas, para Merleau-Ponty (1945/1999), um sentido é imanente ao sensível antes de qualquer juízo. O fenômeno perceptivo oferece uma significação inerente aos signos perceptivos, processo em que o juízo figura apenas como a expressão facultativa e segunda dessa significação.

Merleau-Ponty (1945/1999) defende a tese de que a sintaxe perceptiva articula-se segundo regras próprias, aquém das relações objetivas. A percepção é um ato que, de um só golpe, cria, com a constelação de dados, o sentido que os une. Portanto, não se trata apenas de descobrir um sentido neles, mas, também, de fazer com que tenham um sentido. A percepção é antes de tudo uma potência.

Nesta direção, é necessário enfatizar que o método científico clássico não favorece o conhecimento do homem em uma perspectiva humana. Assim, no tocante à investigação da percepção, faz-se necessária uma revisão geral das categorias propostas pela ciência. Na opinião de Merleau-Ponty, em psicologia deve-se recusar o empirismo, o pensamento causal e o método indutivo, considerado como um simples método das diferenças.

Expliquemos esta posição utilizando o exemplo de pacientes com distúrbios motores acompanhados de deficiência visual, mais especificamente do que se convencionou chamar de cegueira psíquica. Nestes casos, acaba-se por considerar a cegueira psíquica como um caso diferencial do comportamento tátil puro e, assim, somos tentados a concluir que o tocar, por si mesmo, não fornece ao movimento o fundo que lhe é necessário para um funcionamento harmônico. No entanto, para se afirmar que, na cegueira psíquica, os distúrbios motores estão ligados ao distúrbio visual e que, no normal, são os dados visuais os responsáveis pela função de projeção dos movimentos, seria necessário possuir segurança para afirmar que a doença afetou apenas os dados visuais e que as demais condições do comportamento, especialmente a experiência tátil, permaneceram como antes. Isso pode ser afirmado?, pergunta Merleau-Ponty (1945/1999). A deficiência está ligada a uma função mais profunda do que a visão e o tato enquanto soma de qualidades dadas. Ela possui relação com a área vital do sujeito, à sua abertura ao mundo, que faz com que o objeto, mesmo fora de alcance, conte para o normal, exista para ele e faça parte do seu universo motor.
De acordo com a noção de estrutura, é preciso reconhecer que os dados táteis e os dados visuais coexistem no normal e isso os modifica mutuamente, por isso os dados táteis do doente, apartados da contribuição visual, não poderão ser relacionados aos daquele. Dessa forma, não se pode nem mesmo concordar com Goldstein, em quem se apóiam essas análises de Merleau-Ponty, quando afirma a impossibilidade do estudo do tátil puro no normal, mas vê, no doente, “(...) um quadro do que seria a experiência tátil reduzida a si mesma" (Merleau-Ponty, 1945/1999, p. 169), a não ser que se sublinhe o fato de que o pretenso "tátil puro" é um fenômeno patológico que não entra na experiência do normal como um componente.

Mas o fato é que vemos o pensamento indutivo ou causal enclausurar na visão, no tato ou em qualquer outro dado a potência de projeção que habita neles todos e, com isso, “(...) dissimula-a para nós e tornanos cegos para a dimensão do comportamento que é justamente aquela da psicologia" (Merleau-Ponty, 1945/ 1999, p. 170). Dessa maneira, no contexto das questões ora utilizadas como exemplos, para que uma indução permaneça possível, "representação visual" e "percepção tátil" devem agir como causas do movimento, ou como efeitos de alguma outra causa. "Mas se eles não forem isoláveis, se cada um deles pressupuser os outros, o fracasso não caberá ao empirismo ou às tentativas de experiência crucial, mas ao método indutivo ou ao pensamento causal em psicologia" (p. 169). Em outro trecho, o autor diz: "O objeto da psicologia é de tal natureza que não poderia ser determinado por relações de função a variável" (Merleau-Ponty, 1945/1999, p. 165). Os fatos do comportamento são ambíguos, portanto nenhuma experiência é crucial e nenhuma explicação definitiva. O comportamento é uma unidade que configura a potência que é o homem para projetar-se no mundo. Esta é a dimensão do comportamento que cabe à psicologia.

Se o comportamento é uma forma em que os 'conteúdos visuais' e os 'conteúdos táteis', a sensibilidade e a motricidade só figuram a título de momentos inseparáveis, ele permanece inacessível ao pensamento causal, ele só é apreensível por um outro tipo de pensamento - aquele que surpreende seu objeto no estado nascente, tal como ele aparece àquele que o vive, com a 
atmosfera de sentido na qual ele está então envolvido, e que busca introduzir-se nessa atmosfera para reencontrar, atrás dos fatos e dos sintomas dispersos, o ser total do sujeito, se se trata de um normal, o distúrbio fundamental, se se trata de um doente (Merleau-Ponty, 1945/1999, p. 170).

Até aqui, Merleau-Ponty enviou-nos à experiência do ato perceptivo enquanto fundamento do movimento existencial de se situar e de projetar sentidos em nossa circunvizinhança. Nessa investigação do ato perceptivo, o corpo foi revelado como a sede privilegiada da nossa apropriação do mundo. O corpo não é um objeto do mundo, mas o meio de nossa comunicação com ele, diz o autor, e o mundo não é a soma de objetos determinados, mas o horizonte latente de nossa experiência, presente sem cessar, antes de qualquer julgamento.

A psicologia clássica possuía elementos suficientes para distinguir o corpo próprio dos objetos. Por que, então, os psicólogos não efetivaram esta distinção nem extraíram dela nenhuma conseqüência, pergunta Merleau-Ponty (1945/1999). Os psicólogos situavamse no lugar de um pensamento impessoal ao qual a ciência faz referência quando acredita poder separar o que diz respeito à situação do observador e o que diz respeito ao objeto absoluto. Para este pensamento não situado do psicólogo, a experiência do corpo degradava-se em "representações" do corpo, deixando de ser um fenômeno para se transformar em um fato psíquico. Neste sentido, a representação do corpo era uma representação como as outras e, correlativamente, o corpo seria um objeto como os outros.

Ser uma consciência, ou, antes, ser uma experiência, é comunicar interiormente com o mundo, com o corpo e com os outros, ser com eles em lugar de estar ao lado deles. Ocupar-se de psicologia é necessariamente encontrar, abaixo do pensamento objetivo que se move entre as coisas inteiramente prontas, uma primeira abertura às coisas sem a qual não haveria conhecimento objetivo. O psicólogo não podia deixar de redescobrir-se enquanto experiência, quer dizer, enquanto presença sem distância ao passado, ao mundo, ao corpo e ao outro, no momento mesmo em que ele queria perceberse como objeto entre os objetos (MerleauPonty, 1945/1999, p. 142, grifo do autor).

Nosso corpo nos dá um mundo, conforme sinaliza a sua espacialidade, que é diferente da espacialidade objetiva. Ela se dá em situação e nos faz ver que a experiência do corpo nos consagra ao sentido. Movemos nosso corpo fenomenal e não um corpo objetivo. Este corpo fenomenal é dado na relação vivida com o sistema natural do corpo próprio. É assim que um sujeito posto diante de uma tarefa familiar não precisa procurar suas mãos ou seus dedos, pois estes não são objetos a se encontrar no espaço objetivo. Ossos, músculos e nervos são potências já mobilizadas na percepção dos objetos a serem utilizados no trabalho. Vemos que os objetos definem uma certa situação, que exige um certo modo de resolução. Ser no mundo implica em “(...) manter em torno de si um sistema de significações cujas correspondências, relações e participações não precisam ser explicitadas para ser utilizadas" (Merleau-Ponty, 1945/1999, p. 181). Diz o filósofo que a “(...) consciência é o ser para a coisa por intermédio do corpo" (p. 193), é consciência encarnada, o que retira o nosso corpo da região do em si. O filósofo conclui que o intelectualismo encobre a relação orgânica entre o sujeito e o mundo, a transcendência ativa da consciência, o seu movimento de lançar-se em uma coisa e no mundo por meio dos seus órgãos e instrumentos. O sujeito da sensação não é nem um pensador que nota uma qualidade nem um meio inerte afetado por ela; é uma potência que nasce em um certo meio de existência e se sincroniza com ele.

Neste caminho entre os automatismos e as representações, Merleau-Ponty forjou uma noção de existência pela aproximação com a experiência do corpo próprio. Em meio à alternativa entre a causalidade objetiva e o pensamento, o filósofo vislumbrou uma zona vital em que são elaboradas e integradas as possibilidades do indivíduo, sejam as suas possibilidades motoras, perceptivas, sexuais, intelectuais, etc. Trata-se de reconhecer uma estrutura da experiência que reúne esses diversos campos e reclama do corpo os gestos que, integrados à totalidade de uma situação, respondem à sua fisionomia.

Pensemos na percepção de uma situação erótica. Um contexto não adquire uma significação se- 
xual quando é possível representá-lo em relação aos órgãos sexuais ou a estados de prazer. Tampouco estamos lidando com um automatismo. O caso Schneider - paciente de Goldstein que sofrera um ferimento na zona occipital do cérebro - analisado por Merleau-Ponty em diferentes momentos da Fenomenologia da Percepção para mostrar que os problemas neurológicos, mesmo sendo seletivos, alteram a estrutura geral da existência, também é elucidativo a esse respeito. Schneider não perdeu as representações sexuais, nem o aparato fisiológico, estrito senso, porque reagia à estimulação da parceira e podia realizar o intercurso sexual. Mas, se esta atingia o orgasmo e suspendia a relação, Schneider imediatamente perdia o interesse; na verdade seu mundo era neutro afetivamente. De modo que, entre a representação e o automatismo, descobre-se a zona em que o corpo arma a significação erótica da situação, um eros ou uma libido enquanto potência de significação. "Adivinha-se aqui um modo de percepção distinto da percepção objetiva, um gênero de significação distinto da significação intelectual, uma intencionalidade que não é a pura 'consciência de algo"” (Merleau-Ponty, 1945/1999, p. 216).

É assim que, no corpo, a existência se realiza. Os movimentos existenciais de um indivíduo traduzem-se em atitudes, comportamentos e mesmo em processos orgânicos, fatores estes que, portanto, possuem uma significação mais geral em relação ao passado e ao futuro, ao eu e ao outro, enfim, em relação às dimensões primordiais da existência. E MerleauPonty adverte que essa expressão, no corpo, das modalidades da existência não significam da mesma forma que um número designa uma casa: “(...) aqui o signo não indica apenas sua significação, ele é habitado por ela" (Merleau-Ponty, 1945/1999, p. 223). Esta é a maneira que o filósofo encontra para dizer que o corpo encarna o sentido que expressa, assim como um retrato é quase a presença do amigo ausente. $\mathrm{O}$ autor fala de "(...) uma operação primordial de significação em que o expresso não existe separado da expressão e em que os próprios signos induzem seu sentido no exterior" (Merleau-Ponty, 1945/1999, p. 229). O corpo é a expressão da existência no sentido em que nem um nem o outro podem passar pelo original do ser humano. Um pressupõe o outro, o corpo enquanto existência imobilizada e a existência enquanto encarnação perpétua.
Em suma, na Fenomenologia da Percepção, Merleau-Ponty aproximou fisiologia e psiquismo na noção de existência. Para tanto, o filósofo interrogou os conhecimentos produzidos principalmente pela neuro-fisiologia e pela psicologia e acompanhou a explicação causal em seu desenvolvimento científico, buscando “(...) precisar o seu sentido e colocá-la em seu verdadeiro lugar no conjunto da verdade" (Merleau-Ponty, 1945/1999, p. 614). Não refutou, mas se esforçou para compreender as dificuldades próprias do pensamento causal, os seus limites.

Novamente, é importante notar que MerleauPonty faz um uso positivo das investigações científicas na desocultação do sentido dos fenômenos. $\mathrm{Na}$ interação da sua fenomenologia com as ciências em geral, fica claro o quanto a revelação dos fenômenos é árdua e não se confunde sempre com uma descrição imediata do sentido vivido. A fenomenologia não pratica uma espécie de primitivismo cujo objetivo seria o contato originário com o ser independentemente da ciência. O que Merleau-Ponty recusa nas psicologias da "Gestalt" e do behaviorismo é a ontologia implícita de seus fundamentos, e não o sentido de suas experiências, propriamente.

\section{Conclusão}

As críticas de Merleau-Ponty à psicologia da "Gestalt" fundamentam-se no fato de que ela, a despeito de ter tocado no fenômeno originário da percepção através da noção de forma ou estrutura, termina por assumi-lo nos moldes de uma ciência objetiva. Nesse sentido, mais importante do que destacar a crítica do filósofo à teoria do isomorfismo - que pretende reduzir as estruturas perceptivas às estruturas fisiológicas no cérebro, o que representaria o ideal de explicação psicológica -, vale destacar sua crítica ao princípio de uma explicação causal do sentido percebido. Há motivos, diz Merleau-Ponty, para a forma como percebemos o mundo; os elementos que dela fazem parte atuam segundo uma lógica de sentido que a experiência do corpo apreende no seu comércio com o mundo. Mas falar em causa é substituir essa lógica de sentido em que o mundo se abre, por uma representação da natureza, construída pelo pensamento. É substituir e descaracterizar, mais uma vez, a ordem do percebido por uma concepção de ciência que leva, para o fenômeno da percepção, nossas ex- 
plicações sobre o mundo físico, que atribui à percepção aquilo que supomos nos objetos. No caso, que relações objetivas também determinariam nossa visão. Mas, como disse Descartes, seria preciso, então, supor uma alma ao fim desse processo, pois, afinal, alguém tem que ver.

Como não se trata, para Merleau-Ponty, de substituir o objetivismo pelo espiritualismo, devemos refazer nossa noção de percepção, e foi essa a tarefa que Merleau-Ponty assumiu por toda a vida. Por ora, assinalemos, em primeiro lugar, que se trata de descrever, e não de explicar. Esse "leitmotiv" fenomenológico não é assumido por Merleau-Ponty como princípio de uma filosofia transcendental que descobre no "cogito" a possibilidade de todo fenômeno. Merleau-Ponty não se furtou, nesse sentido, ao debate do sentido dos fenômenos físico, vital e humano para revelar seus encadeamentos e rupturas, com o que procurou mostrar tanto a inscrição quanto a especificidade e irredutibilidade do sentido percebido às outras duas ordens. Com isso, fundou a descrição como atividade apropriada e conquistadora do sentido percebido - linguagem que aproximou a filosofia de Merleau-Ponty da literatura -, e reconheceu que as indeterminações, ambigüidades e imprecisões de sentido fazem parte da lógica do mundo percebido. Como vimos, todo este percurso do filósofo foi fundado nos resultados de trabalhos que vinham sendo realizados no campo da psicologia e no de outras ciências. Por sua vez, tais áreas do conhecimento receberam, com a obra de Merleau-Ponty, significativas contribuições cujo alcance permanece sendo explorado.

\section{Referências}

Bimbenet, E. (2004). Nature e humanité: Le probléme anthropologique dans l'ouvre de MerleauPonty. Paris: Livrairie Philosophique J. Vrin.

Coelho Júnior, N., \& Carmo, P. (1991). MerleauPonty: Filosofia como corpo e existência. São Paulo: Escuta.

Guillaume, P. (1966). Psicologia da forma (2a ed.). São Paulo: Nacional. (Original publicado em 1937).

Japiassu, H. (1977). Introdução à epistemologia da psicologia (2a ed.). Rio de Janeiro: Imago.
Lefort, C. (2003). Posfácio. In M. Merleau-Ponty, $O$ visivel e o invisivel (4a ed. pp. 247-267). São Paulo: Perspectiva.

Merleau-Ponty, M. (1975). A estrutura do comportamento. Belo Horizonte: Interlivros. (Original publicado em 1942).

Merleau-Ponty, M. (1990). O primado da percepção e suas conseqüências filosóficas. Campinas, SP: Papirus.

Merleau-Ponty, M. (1999). Fenomenologia da percepção ( $2 \mathrm{a}$ ed.). São Paulo: Martins Fontes. (Original publicado em 1945).

Merleau-Ponty, M. (2003). O visivel e o invisivel (4a ed.). São Paulo: Perspectiva.

Politzer, G. (1975). Crítica dos fundamentos da psicologia (2a ed.). Lisboa: Presença. (Original publicado em 1929).

Schultz, D., \& Schultz, S. (1995). História da psicologia moderna (7a ed.). São Paulo: Cultrix.

Artigo recebido em 06/06/2006.

Aceito para publicação em 23/11/2006.

Endereço para correspondência:

Danilo Saretta Verissimo. Rua General Rondon, 26 apto 53, Aparecida. CEP: 11030-570, Santos-SP, Brasil. E-mail: dsverissimo@pg.ffclrp.usp.br

Danilo Saretta Verissimo é doutorando em Psicologia pelo Departamento de Psicologia e Educação da Faculdade de Filosofia, Ciências e Letras de Ribeirão Preto/USP e doutorando pela Faculdade de Filosofia da Universidade Jean Moulin - Lyon III, França, bolsista CAPES.

Reinaldo Furlan é docente dos cursos de Graduação e de Pós-Graduação em Psicologia do Departamento de Psicologia e Educação da Faculdade de Filosofia, Ciências e Letras de Ribeirão Preto/USP. 